OPEN ACCESS

Edited by:

Lijie Guo,

Beijing General Research Institute of Mining and Metallurgy, China

Reviewed by:

Chen Qiusong,

Central South University, China

Jiaqi Li,

University of California, Berkeley,

United States

*Correspondence:

Chen Chao

13931501518@163.com

Specialty section: This article was submitted to

Structural Materials,

a section of the journal

Frontiers in Materials

Received: 11 June 2021

Accepted: 05 July 2021

Published: 06 August 2021

Citation:

Deqing G, Hongbao L, Chao C, Hongjian $L$ and Youzhi $Z$ (2021) An

Experimental Study on Strength

Characteristics and Hydration Mechanism of Cemented Ultra-Fine

Tailings Backfill.

Front. Mater. 8:723878.

doi: $10.3389 /$ fmats.2021.723878

\section{An Experimental Study on Strength Characteristics and Hydration Mechanism of Cemented Ultra-Fine Tailings Backfill}

\author{
Gan Deqing, Li Hongbao, Chen Chao *, Lu Hongjian and Zhang Youzhi \\ College of Mining Engineering, North China University of Science and Technology, Tangshan, China
}

In order to study the strength characteristics and hydration mechanism of the cemented ultra-fine tailings backfill (CUTB), the uniaxial compressive strength (UCS) tests of CUTB and cemented classified tailings backfill (CCTB) with cement-tailing ratio ( $C / T$ ratio) of 1:4 and $1: 6$ and curing ages of $3,7,14$ and 28 days were carried out. The hydration products and morphology of the cemented paste backfill (CPB) were analyzed by X-ray diffraction (XRD) and scanning electron microscope (SEM). The results show that the UCS of the CUTB is significant compared to the CCTB under the same conditions; the greater the $\mathrm{C} / \mathrm{T}$ ratio and curing age, the greater the UCS difference value. The UCS growth curve of the CUTB is approximately S-shaped, and there is a relationship between the UCS and curing age. The ultra-fine tailings particles in the CUTB have potential activity; in the alkaline environment-generated cement hydration, active $\mathrm{SiO}_{2}$ and $\mathrm{Al}_{2} \mathrm{O}_{3}$ particles undergo secondary hydration reaction, resulting in no or very little $\mathrm{Ca}(\mathrm{OH})_{2}$ crystals generated in the CUTB, and the hydration products and morphology are also different.

Keywords: cemented ultra-fine tailings backfill, uniaxial compressive strength, regression equation, hydration mechanism, secondary hydration reaction

\section{INTRODUCTION}

The ultra-fine particles of mineral monomer exist in iron ore; therefore, iron ore must be ground to ultra-fine size to separate minerals and gangue (Deng et al., 2017a). The tailings particles discharged after mineral processing of the concentration plant are extremely fine, classified as ultra-fine tailings (UT). The tailings are usually discharged into the tailing pond or transported to the backfill plant to be used as cemented aggregates (Wang et al., 2014).

Generally speaking, the uniaxial compressive strength (UCS) of cemented paste backfill (CPB) is mainly determined by the cement-tailing ratio ( $\mathrm{C} / \mathrm{T}$ ratio), mass concentration, and curing age. Taking the underground mining environment into consideration, the UCS is affected by many factors such as temperature and mixing water (Benzaazoua et al., 2004; Fall et al., 2010; Yilmaz et al., 2012; Ercikdi et al., 2013; Jiang et al., 2019). The classified tailings have gotten promising results in $\mathrm{CPB}$ for several years, making the technological process more perfect. In recent years, the study is aimed at studying specific mines, focusing on the proportioning scheme optimization under the premise of satisfying UCS, ore recovery rate and settlement, and the rheological characteristics and transport characteristics of the filling slurry (Wang et al., 2009; Liu et al., 2019). The design optimization of mine filling process parameters and reasonable adjustment of the proportioning scheme in $\mathrm{CPB}$ can reduce the amount of cementing materials and improve the utilization of tailing 
(Lu et al., 2018). In addition, some experts measured and analyzed the stress state and pore water pressure of underground $\mathrm{CPB}$, indicating that filling and settlement time schedules have a significant impact on the pore water pressure of the cemented backfill, which in turn affects the quality of CPB (Doherty et al., 2015). The constitutive model and percolation model of CPB contributing to the efficient use of tailings are also studied (Helinski et al., 2007). Some of the industrial waste byproducts, including fly ash, slag, water granulated slag, and limestone powder, have been applied as potential active materials to $\mathrm{CPB}$ to reduce cement consumption and reduce filling costs (Ouellet et al., 2007; Wang et al., 2009; Cihangir et al., 2012; Yin et al., 2012; Zheng et al., 2016; Deng et al., 2017b). Many studies have shown that the choice of cement type also affects the UCS of CPB (Ercikdi et al., 2009; Xue et al., 2018).

The traditional research of $\mathrm{CPB}$ is based on the theory of building materials; the aggregates are not allowed to contain a large amount of ultra-fine particles. With the extensive application of classified tailings, a series of problems have arisen: low utilization of tailing, polluted underground environment, long cycle of filling mining, and high filling costs. Therefore, many studies have been carried out to analyze the fineness of tailings on the quality of CPB (Kesimal et al., 2003; Fall et al., 2005; Fall et al., 2008; Yilmaz et al., 2014; Ke et al., 2015; Ke et al., 2016). In recent years, with the increase of UT output, there are some signs of progress in relevant research. Kawatra has analyzed the mineral composition and particles morphology of UT in several regions (Kawatra, 2017). Wang et al. have investigated and analyzed the current status of UT, also discussed the key technical problems of slow settlement rate and the low water recovery rate in the recycling of UT, and proposed a solution (Wang et al., 2014). The theoretical and applied research on UT is currently concentrated on the rheological characteristics and conveying characteristics of slurry. Many experimental studies have been carried out on the influencing factors, parameter optimization, and transportation performance optimization (Yang et al., 2017; Zhou et al., 2017a; Zhou et al., 2017b; Deng et al., 2018a; Deng et al., 2018b). There is less literature on the UCS of cement ultra-fine tailings backfill (CUTB). Qiu et al. have researched the effect of $\mathrm{C} / \mathrm{T}$ ratio, mass concentration, and curing age on the UCS of CUTB. The results show that UT has certain activity and the curing age is the most important factor affecting UCS, followed by the C/T ratio and mass concentration (Qiu et al., 2017). Niroshan et al. have designed a uniaxial compressive strength test with different cementitious materials and contents and found that CUTB of slag + cement had a higher early strength. Compared with $\mathrm{CPB}$, CUTB of slag and cement had a higher stiffness, summing up the prediction model of UCS (Nircoshan et al., 2017). Based on the UCS test and the physicochemical properties of UT, Xu et al. have discussed the diagenesis mechanism of CUTB (Xu et al., 2013).

Most of the current research involved the application and optimization material of UT and the cemented backfill to UT; however, few studies discussed the strength characteristics and the hydration reaction mechanism of CUTB. Because the particles sizes of most UT are smaller than those of cement particles, the strength formation mechanism and hydration reaction of CUTB are different from CCTB, which is essentially different. Therefore, it is very important to research the strength characteristics and hydration reaction mechanism of CUTB. In this article, the ultra-fine tailings and classified tailings of iron were used as experimented materials. Based on the analysis of the basic physical and chemical properties, the strength experiment of different schemes of CPB was designed, the strength variation law of CUTB analyzed, and a prediction model based on the strength value of tailings gradation characteristics and curing age constructed. X-ray diffraction (XRD) and scanning electron microscope (SEM) were used to compare and analyze the hydration products of different $\mathrm{CPB}$, research the hydration reaction mechanism of CUTB, and discuss the strength formation mechanism of CUTB.

\section{MATERIALS AND METHODS}

\section{Test Material}

\section{Tailings}

The test materials are the ultra-fine tailings and the classified tailings in an iron ore mine in northern North China. The composition of the tailings is shown in Figure $\mathbf{1}$ and Table $\mathbf{1}$. The size of the median grain of the ultra-fine tailings is $14.97 \mu \mathrm{m}$, and the restricted rain size is $20.7 \mu \mathrm{m}$, and it is classified into UT according to the Design Reference Materials for Tailing Facilities. The median grain size of the classified tailings is $190.78 \mu \mathrm{m}$, and the restricted grain size is $269.5 \mu \mathrm{m}$. The coefficients of uniformity for the two types of tailings are 5.88 and 5.12, respectively. The coefficients of curvature for the two types of tailings are 1.1 and 0.86 , respectively (Xu et al., 2013). The two types of tailings belong to the better gradation tailings.

Figure 2 shows that the ultra-fine tailings are mainly composed of cohesive particles and powder particles, containing a small number of sand particles, and the shape of the particles is mostly irregular (Wolff et al., 2011). The surface of the particles is smooth with large surface energy. There is an agglomeration phenomenon found in the ultra-fine tailings (Wolff et al., 2011). The classified tailings are composed of sand particles. The surface of the particles is relatively rough, mostly the crystal grain boundary surface and a small amount of staggered fracture surface. A small number of cohesive particles and powder particles attach to the surface of sand particles.

Figure 3 shows the XRD spectrum results. The tailings contain a large amount of $\mathrm{SiO}_{2}$ (Wolff et al., 2011), which belongs to high silicon tailings, and contain $\mathrm{MgO}, \mathrm{CaO}, \mathrm{Al}_{2} \mathrm{O}_{3}$, and total $\mathrm{Fe}$. Figure 3 also shows that the intensity of the diffraction peak of the classified tailings is greater than that of the ultra-fine tailings; especially, the main diffraction peak of $\mathrm{SiO}_{2}$ is significant. The intensity of the main diffraction of $\mathrm{SiO}_{2}$ in the classified tailings is about 15,000 , while the main diffraction peak intensity of $\mathrm{SiO}_{2}$ in the ultra-fine tailings is less than 9,000. It can be seen that the ultra-fine tailings particles have a low degree of crystallization, and the amorphous particles have high surface energy, high content, and large specific surface area, so the activity of the ultra-fine is relatively higher than that of the classified tailings. 

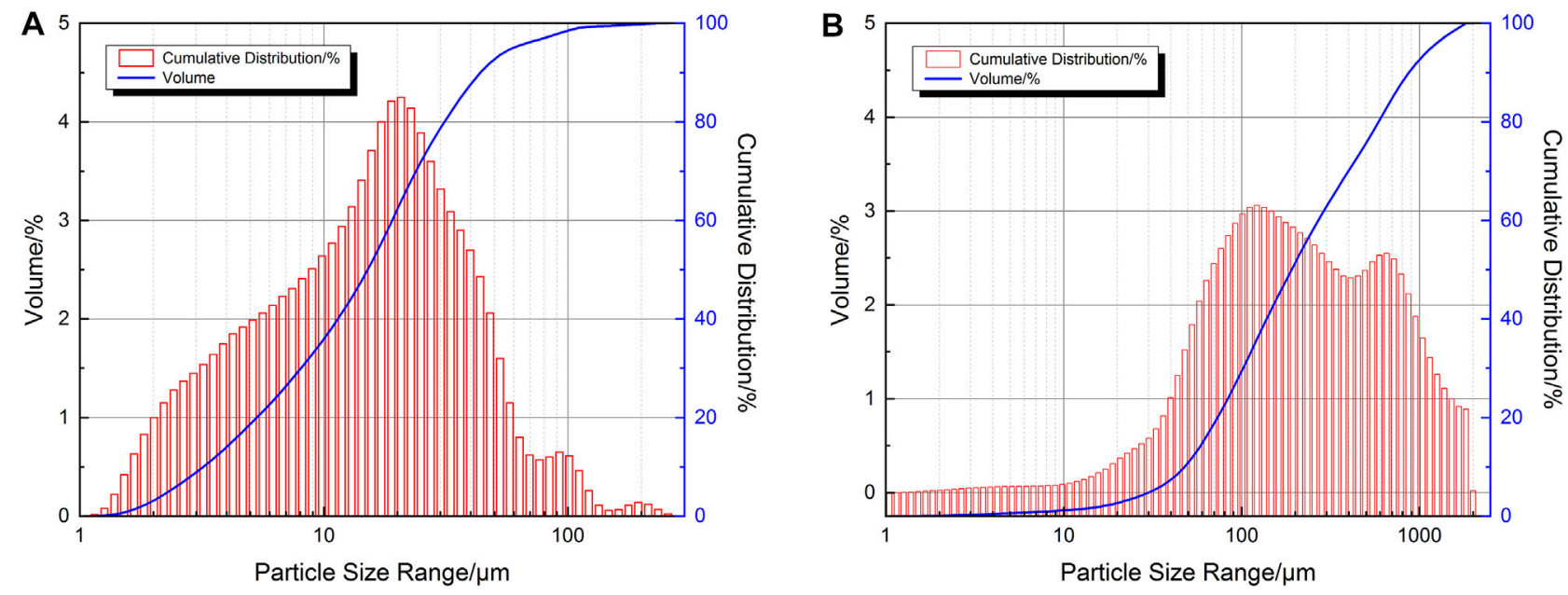

FIGURE 1 | Grain size distribution curve of tailing: (A) the ultra-fine tailings; (B) the classified tailings.

TABLE 1 | Physical and chemical characterization of the tailings and binder.

\begin{tabular}{|c|c|c|c|c|}
\hline \multicolumn{2}{|l|}{ Characteristics } & \multirow{2}{*}{$\begin{array}{c}\text { The ultra-fine tailings } \\
67.58 \%\end{array}$} & \multirow{2}{*}{$\begin{array}{c}\text { The classified tailings } \\
74.24 \%\end{array}$} & \multirow{2}{*}{$\begin{array}{l}\text { Binder } \\
20.8 \%\end{array}$} \\
\hline Chemical composition & $\mathrm{SiO}_{2}$ & & & \\
\hline & $\mathrm{MgO}$ & $5.60 \%$ & $3.34 \%$ & $3.23 \%$ \\
\hline & $\mathrm{CaO}$ & $4.04 \%$ & $2.96 \%$ & $56.2 \%$ \\
\hline & $\mathrm{Al}_{2} \mathrm{O}_{3}$ & $7.30 \%$ & $7.65 \%$ & $10.0 \%$ \\
\hline & $\mathrm{Fe}_{2} \mathrm{O}_{3}$ & - & - & $4.4 \%$ \\
\hline & $\mathrm{SO}_{3}$ & - & - & $2.49 \%$ \\
\hline & Total Fe & $6.00 \%$ & $4.29 \%$ & - \\
\hline & Total & $90.52 \%$ & $92.48 \%$ & 97.12 \\
\hline & Alkalinity coefficient & 0.13 & 0.08 & - \\
\hline & Quality coefficient & 0.25 & 0.19 & - \\
\hline & Activity coefficient & 0.06 & 0.04 & - \\
\hline \multirow[t]{5}{*}{ Physical properties } & Effective grain size $\left(\mathrm{d}_{10} / \mu \mathrm{m}\right)$ & 3.52 & 52.62 & 1.55 \\
\hline & Median grain size $\left(d_{50} / \mu \mathrm{m}\right)$ & 14.97 & 190.78 & 14.1 \\
\hline & Control grain size $\left(\mathrm{d}_{60} / \mu \mathrm{m}\right)$ & 20.7 & 269.5 & 17.3 \\
\hline & Coefficient of uniformity (Cu) & 5.88 & 5.12 & 11.16 \\
\hline & Coefficient of curvature (Cc) & 1.10 & 0.86 & 1.13 \\
\hline
\end{tabular}

Table 1 also shows the main chemical components of tailings, the mass ratios of $90.52 \%$ (the ultra-fine tailings) and $92.48 \%$ (the classified tailings). The ultra-fine tailings have an alkalinity coefficient of 0.13 , which belongs to the acidic tailings. The quality coefficient of the ultra-fine tailings is 0.25 ; the quality is a little poor. The activity coefficient of the ultra-fine tailings is 0.06; the ultra-fine tailings have a lower activity (Xu et al., 2013).

\section{Binder}

The cement used in the tests is the production batch of Jidong brand ordinary Portland cement (325\#), which was produced in Tangshan city, Hebei Province, China.

\section{Mixing Water}

The tailings discharged from the plant contain water. In the test preparation stage, the tailings were placed into a drying box to be dried; then, they will be naturally cooled at room temperature to avoid the influence of moisture in the tailings on the test
(Benzaazoua et al., 2004). Tap water from Lunan District of Tangshan City was used as mixing water to mix binder and tailings and prepare ultra-fine tailings backfill slurry.

\section{Uniaxial Compressive Strength Tests}

\section{Experiment Mixing Ratio}

According to the research experience and application (Qiu et al., 2017 ), the $C / T$ ratios were $1: 4$ and $1: 6$, and the curing age was 3,7 , 14 , and 28 days. Because of the obvious difference at the same mass concentration of the ultra-fine tailings and the classified tailings, the mass concentration was determined to be $70 \%$.

\section{Experiment Method}

According to the experiment scheme, calculate and weigh the quality of cement and tailings. Then, they will be mixed evenly and poured into the mixing vessel. After that, add water and mix for 2 min to complete the backfill slurry. The backfill slurry is injected into the standard triple test strip of $7.07 \mathrm{~cm} \times 7.07 \mathrm{~cm} \times 7.07 \mathrm{~cm}$ 
A

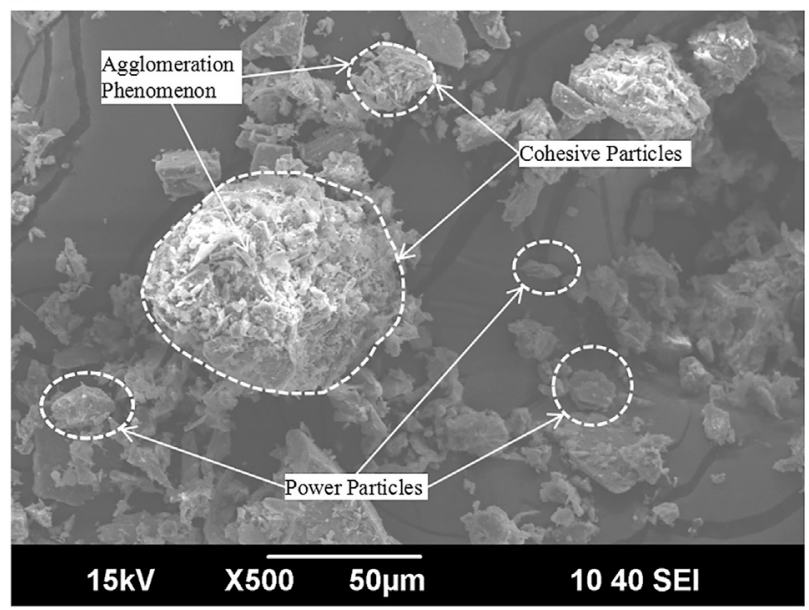

B

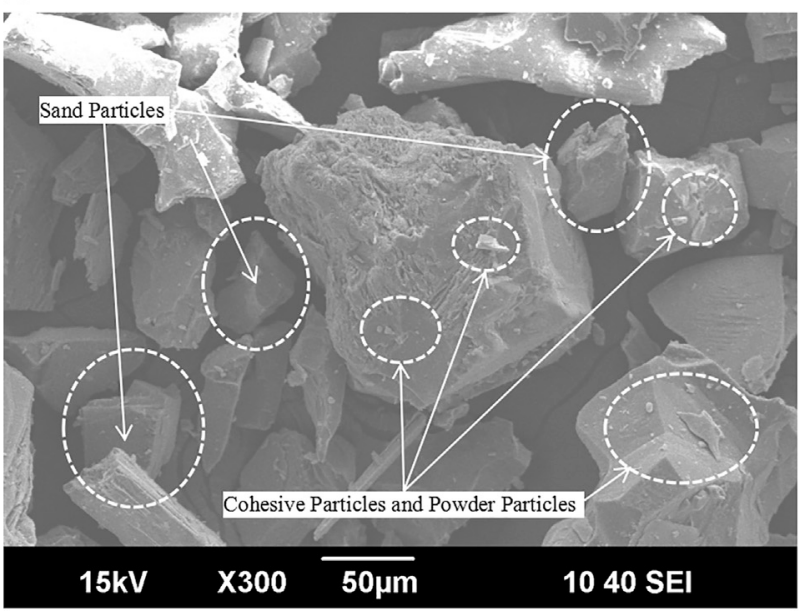

FIGURE 2 | SEM images of the tailings: (A) the ultra-fine tailings; (B) the classified tailings.
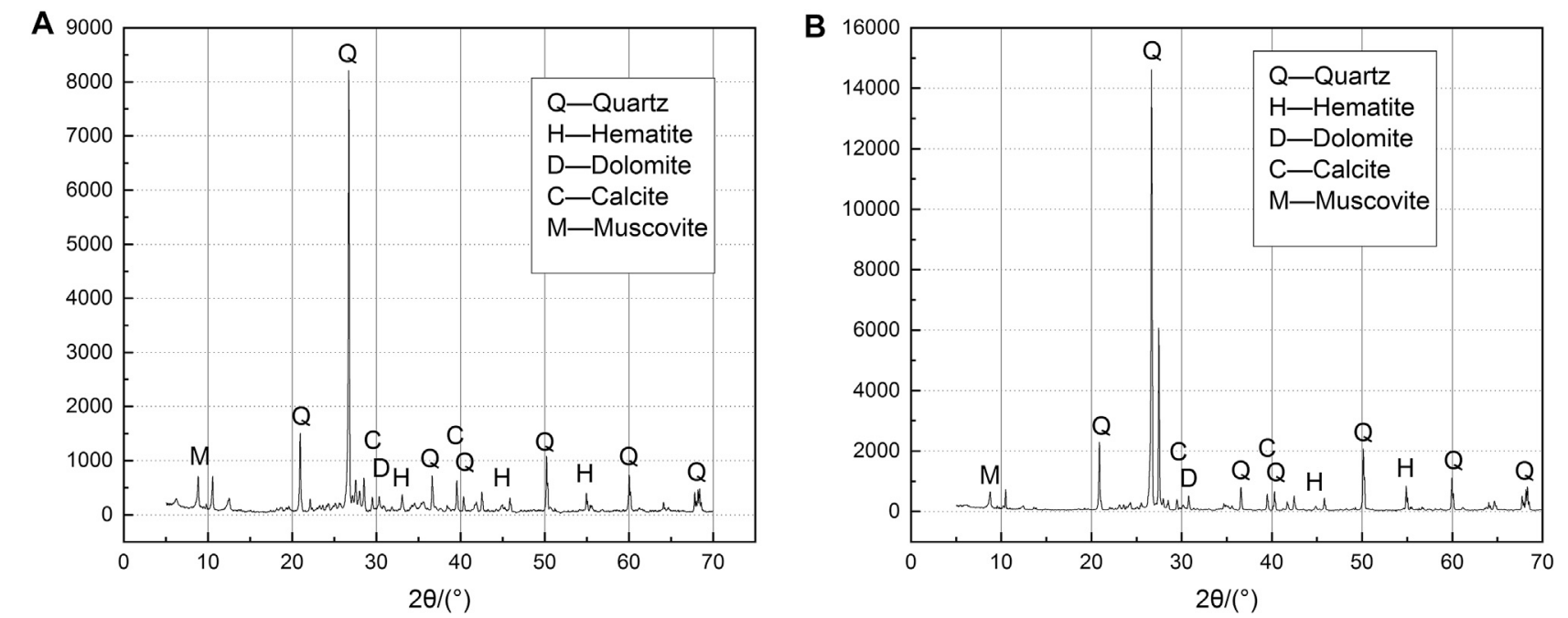

FIGURE 3 | XRD spectrum results of tailings: (A) the ultra-fine tailings; (B) the classified tailings.

(Xue et al., 2018). After being tamped and smoothed, it will be placed in the curing box for $24 \mathrm{~h}$ and then demolded. The CPB was numbered and labeled and then placed in the curing box for maintenance. The curing environment temperature is $20 \pm 1^{\circ} \mathrm{C}$, the relative humidity is $90 \%$, and the curing time is controlled according to the experimental scheme. The cured CPB was placed on the test platform of the uniaxial press, aligned with the axis. To determine the UCS of the backfill, each group of CPB is measured 3 times and averaged (Fall et al., 2005).

\section{XRD and SEM}

After the uniaxial compressive strength test, the internal samples of $\mathrm{CPB}$ were stored in a sealed bottle containing anhydrous ethanol. The purpose is to replace the moisture in the CPB sample and terminate the hydration reaction. A small amount of $\mathrm{CPB}$ in the sealed bottle was taken out and naturally air-dried, than ground to about 200 mesh. The scanning angle was $5^{\circ}-7^{\circ}$ and the scanning speed was $0.02^{\circ} / \mathrm{min}$ by X-ray diffractometer (Bruker D8 ADVANCE) (Fall et al., 2005). Another complete sample of $\mathrm{CPB}$ in the sealed bottle was taken and naturally air-dried. The microscopic morphology of the original fracture surface of $\mathrm{CPB}$ was taken by the scanning electron microscope (JSM-6390A), and the acceleration voltage was $15 \mathrm{kV}$ (Fall et al., 2005).

\section{RESULTS AND DISCUSSION}

\section{UCS Variation Law of CUTB}

At present, domestic and foreign researchers generally believe that the higher the proportion of cement and the longer the 

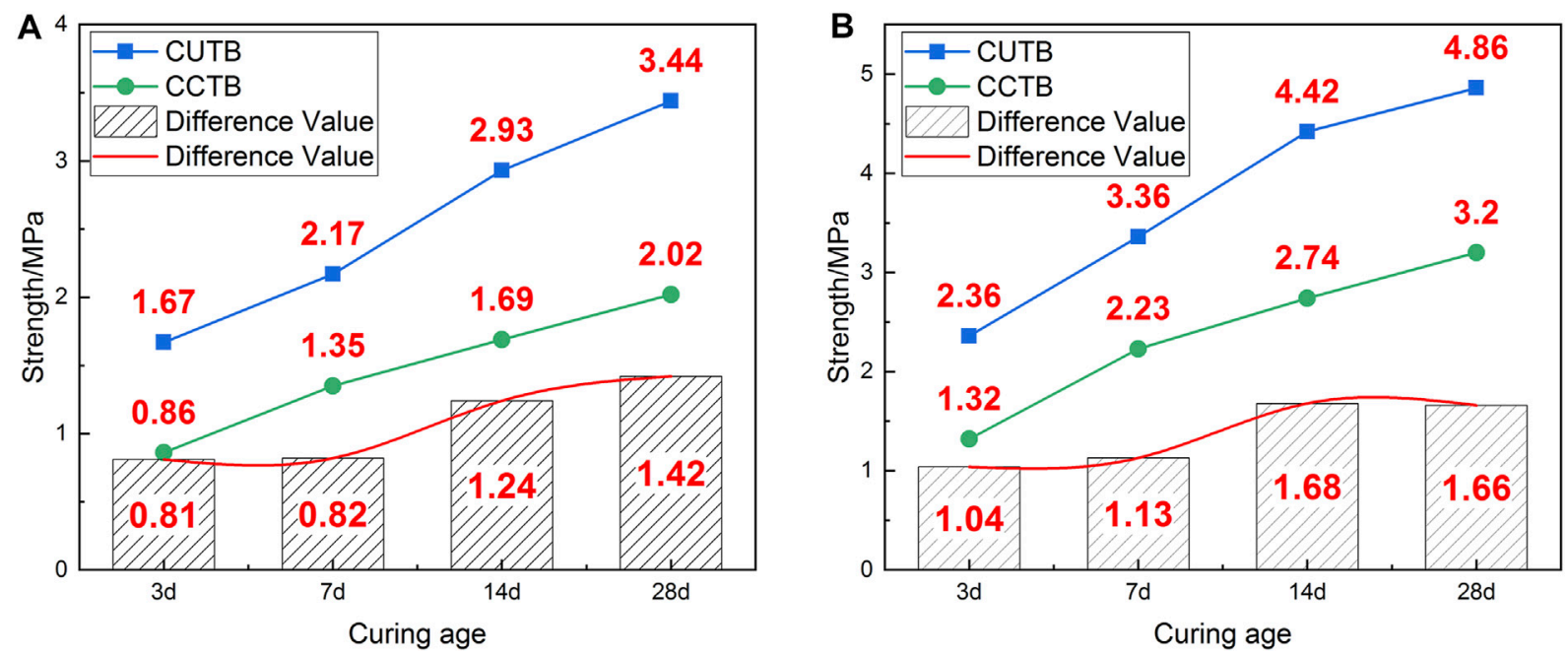

FIGURE 4 | UCS and difference value (DV) of CPB with different mixing ratios: (A) C/T ratio 1:6; (B) C/T ratio 1:4.

TABLE 2 | UCS of CPB with different mixing ratio.

\begin{tabular}{|c|c|c|c|c|c|}
\hline Number & Mass concentration (\%) & $\mathrm{C} / \mathrm{T}$ ratio & Tailings & Curing age (d) & UCS/MPa \\
\hline 1 & 70 & $1: 4$ & UT & 3 & 2.36 \\
\hline 2 & 70 & $1: 4$ & UT & 7 & 3.36 \\
\hline 3 & 70 & $1: 4$ & UT & 14 & 4.42 \\
\hline 4 & 70 & $1: 4$ & UT & 28 & 4.86 \\
\hline 5 & 70 & $1: 6$ & UT & 3 & 1.67 \\
\hline 6 & 70 & $1: 6$ & UT & 7 & 2.17 \\
\hline 7 & 70 & $1: 6$ & UT & 14 & 2.93 \\
\hline 8 & 70 & $1: 6$ & UT & 28 & 3.44 \\
\hline 9 & 70 & $1: 4$ & CT & 3 & 1.32 \\
\hline 10 & 70 & $1: 4$ & CT & 7 & 2.23 \\
\hline 11 & 70 & $1: 4$ & CT & 14 & 2.74 \\
\hline 12 & 70 & $1: 4$ & CT & 28 & 3.20 \\
\hline 13 & 70 & $1: 6$ & CT & 3 & 0.86 \\
\hline 14 & 70 & $1: 6$ & CT & 7 & 1.35 \\
\hline 15 & 70 & $1: 6$ & CT & 14 & 1.69 \\
\hline 16 & 70 & $1: 6$ & CT & 28 & 2.02 \\
\hline
\end{tabular}

curing age, the greater the UCS of the CPB (Kesimal et al., 2003). Figure 4 and Table 2 show that the CUTB also follows the rule in terms of $\mathrm{C} / \mathrm{T}$ ratio and curing age.

Figure 4 also shows that the UCS of the CUTB is significantly higher than the CCTB at the same conditions and the greater the $\mathrm{C} / \mathrm{T}$ ratio, the greater the UCS difference value. When the $\mathrm{C} / \mathrm{T}$ ratio is $1: 6$, the UCS differences value of $\mathrm{CPB}$ are $0.81 \mathrm{MPa}$ (3 days), $0.82 \mathrm{MPa}$ (7 days), $1.24 \mathrm{MPa}$ (14 days), and $1.42 \mathrm{MPa}$ (28 days), and the average value is $1.07 \mathrm{MPa}$. Moreover, when the $\mathrm{C} / \mathrm{T}$ ratio is $1: 4$, the UCS differences value of $\mathrm{CPB}$ are $1.04 \mathrm{MPa}$ (3 days), $1.13 \mathrm{MPa}$ (7 days), $1.68 \mathrm{MPa}$ (14 days), and $1.66 \mathrm{MPa}$ (28 days), and the average value is $1.38 \mathrm{MPa}$. With the increase of the curing age, when the UCS difference value increases, the ultrafine tailings are more conducive to the increase of UCS in the CUTB and increase faster than those of the CCTB. Especially during the curing age of 7-14 days, the UCS differences value increases by $0.42 \mathrm{MPa}(\mathrm{C} / \mathrm{T}$ ratio $1: 6)$ and $0.55 \mathrm{MPa}(\mathrm{C} / \mathrm{T}$ ratio $1: 4)$, respectively, and the UCS difference value of the CUTB increases sharply, which is approximately an S-shaped curve. With the increase of the $\mathrm{C} / \mathrm{T}$ ratio (cement content), the UCS difference value of the CUTB increases. When the C/T ratio is $1: 6$, the UCS difference value of CUTB is $1.07 \mathrm{MPa}$, and when the $\mathrm{C} / \mathrm{T}$ ratio is 1 : 4 , the UCS difference value is $1.38 \mathrm{MPa}$. It shows that the CUTB is more sensitive to the change of cement content, increasing the same quality of cement; the UCS of CUTB increases more.

Figure 5 shows that the UCS variation laws of the CUTB and the CCTB are different under the same mixing ratio. The CUTB has a relatively large early strength, which reaches $1.67 \mathrm{MPa}$ at a $\mathrm{C} / \mathrm{T}$ ratio of 1:6 and a curing age of 3 days. Under the same mixing ratio, the UCS of the CCTB is only $0.86 \mathrm{MPa}$. The UCS growth curve of the CUTB is approximately S-shaped, and during the curing age of 3 7 days, the UCS growth rate of the CUTB is slow, 

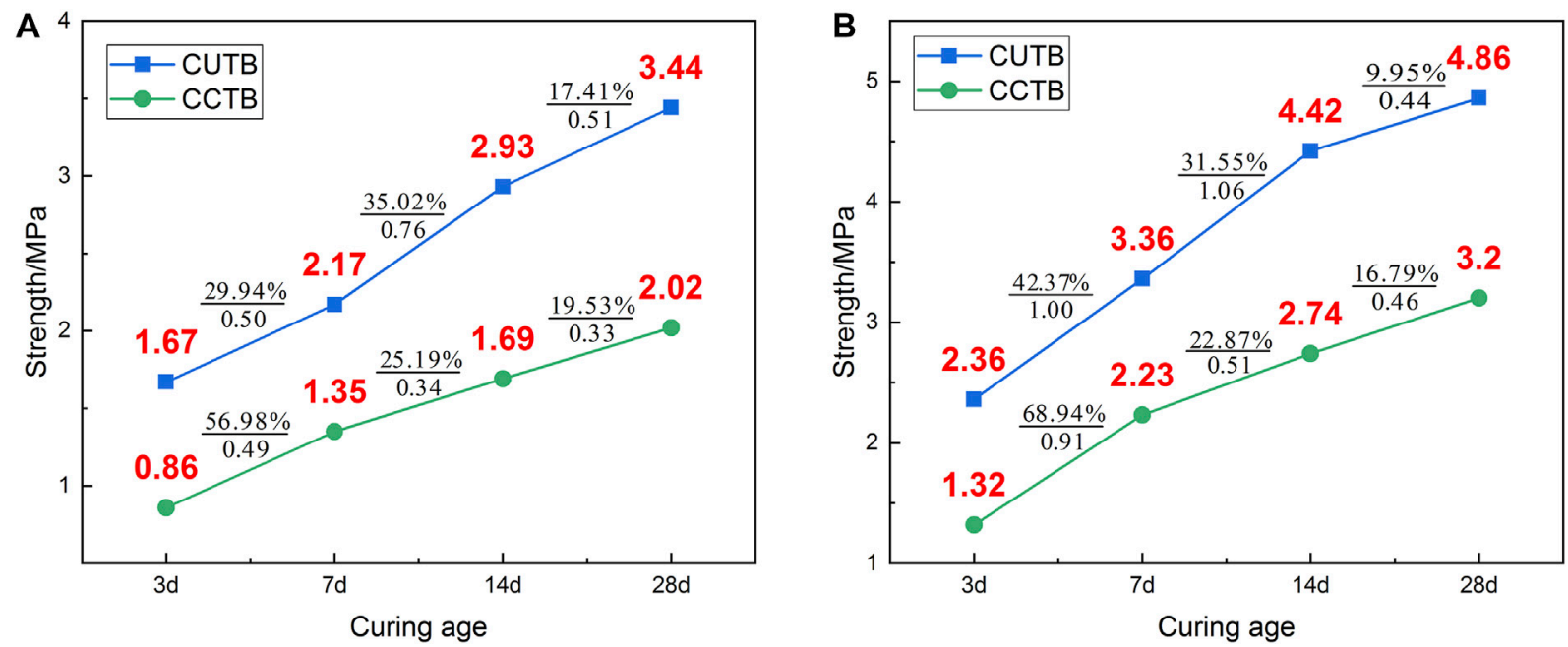

FIGURE 5 | UCS variation law of CPB with different mixing ratios: (A) C/T ratio 1:6; (B) C/T ratio 1:4.
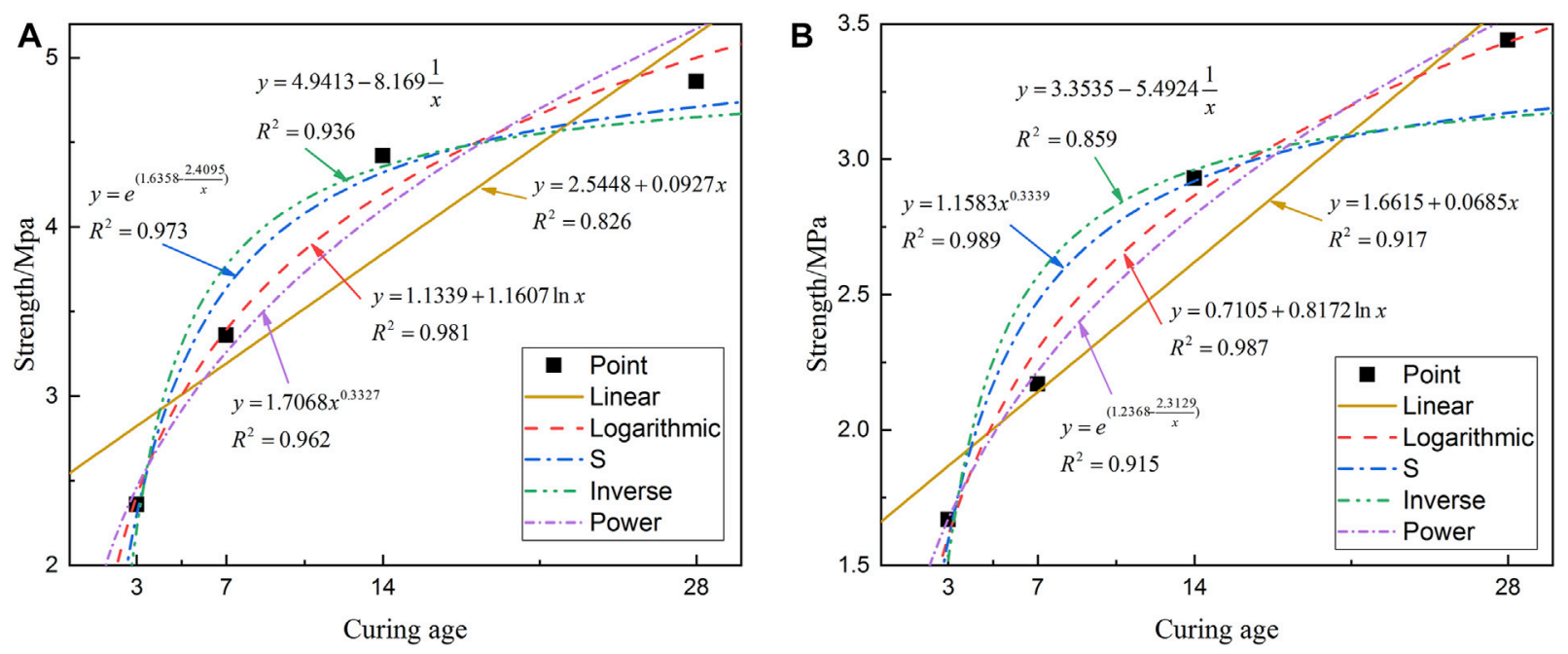

FIGURE 6 | Fitting curve and regression equation of UCS with curing age: (A) C/T ratio 1:6; (B) C/T ratio 1:4.

with an increase of $0.5 \mathrm{MPa}(29.94 \%)$. The UCS growth rate of the CUTB is accelerated during the curing age of 7-14 days, with an increase of $0.76 \mathrm{MPa}(35.02 \%)$. In the later period of curing age (14-28 days), the UCS growth rate of the CUTB decreases, with an increase of $0.51 \mathrm{MPa}(17.41 \%)$. In contrast, the UCS growth curve of the CCTB is of an approximately convex shape, and the UCS growth rate decreases with curing age. When the $\mathrm{C} / \mathrm{T}$ ratio is $1: 6$, the UCS growth rate of CCTB is $0.49 \mathrm{MPa}(56.98 \%)$, $0.34 \mathrm{MPa}(25.19 \%)$, and $0.33 \mathrm{MPa}$ (19.53\%), respectively.

\section{UCS Regression Fitting of CUTB}

Figure 6 shows that there is a nonlinear relationship between the UCS and curing age of CUTB. According to the variation law of UCS and curing age of CUTB, the least-square method is used for curve regression analysis and to obtain a significant regression equation. The function expression of regression equation is as follows:

$$
\widehat{P}_{k}=f\left(T_{k}, b_{1}, b_{2}, \cdots, b_{m},\right),
$$

where $\widehat{P}_{k}$ is regression value of UCS, $T_{k}$ is curing age, and $b_{1}, b_{2}, \cdots$, $b_{m}$ are regression parameters.

The principle of the least-square method is to minimize the sum of squares deviations between all observed values and regression values:

$$
Q\left(b_{1}, b_{2}, \cdots, b_{m}\right)=\sum_{i=1}^{n}\left\{P_{k}-f\left(T_{k}, b_{1}, b_{2}, \cdots, b_{m},\right)\right\}^{2},
$$

where $Q\left(b_{1}, b_{2}, \cdots, b_{m}\right)$ is the sum of squares deviations and $P_{k}$ is the observation value. 
TABLE 3 | Regression equation and test results.

\begin{tabular}{|c|c|c|c|c|c|c|c|}
\hline $\mathrm{C} / \mathrm{T}$ ratio & Equation type & Expression & $\mathbf{R}$ & $\mathbf{R}^{2}$ & ADJ $R^{2}$ & $\mathbf{F}$ & $p$ \\
\hline \multirow[t]{5}{*}{$1: 4$} & Linear & $P=2.5448+0.0927 T$ & 0.909 & 0.826 & 0.739 & 9.5153 & 0.091 \\
\hline & Logarithmic & $P=1.1339+1.1607 \ln T$ & 0.99 & 0.981 & 0.971 & 100.8506 & 0.0098 \\
\hline & $S$ & $P=e^{(1.6}$ & 0.986 & 0.973 & 0.960 & 72.1308 & 0.0136 \\
\hline & Inverse & $P=4.9413-8.169 \frac{1}{T}$ & 0.968 & 0.936 & 0.904 & 29.3922 & 0.0324 \\
\hline & Power & $P=1.7068 T^{0.3327}$ & 0.981 & 0.962 & 0.943 & 51.0318 & 0.019 \\
\hline \multirow[t]{5}{*}{$1: 6$} & Linear & $P=1.6615+0.0685 T$ & 0.957 & 0.917 & 0.874 & 21.9546 & 0.0427 \\
\hline & Logarithmic & $P=0.7105+0.8172 \ln T$ & 0.993 & 0.987 & 0.980 & 147.1173 & 0.0067 \\
\hline & $S$ & $P=e^{\left(1.2368-\frac{2.3129}{T}\right)}$ & 0.957 & 0.915 & 0.873 & 21.6065 & 0.0433 \\
\hline & Inverse & $P=3.3535-5.4924 \frac{1}{T}$ & 0.927 & 0.859 & 0.788 & 12.1806 & 0.0732 \\
\hline & Power & $P=1.1583 T^{0.3339}$ & 0.994 & 0.989 & 0.984 & 187.3661 & 0.0053 \\
\hline
\end{tabular}

The parameters of different curve regression equations are calculated, and the method of variance analysis is selected for statistical analysis. Then, the correlation coefficients (R), coefficient of determinations $\left(\mathrm{R}^{2}\right)$, and adjusted coefficient of determinations (ADJ $\mathrm{R}^{2}$ ) of different regression equations are obtained, as well as the $\mathrm{F}$ values and $p$ values of the significance test. The specific calculation results are shown in Table 3.

Table 3 shows that the linear regression equation between UCS and curing age of the CUTB at the C/T ratio of 1:4 and 1:6 is relatively low, and the adjusted coefficients of determinations are only 0.739 and 0.874 , indicating that the UCS of CUTB is nonlinear with the curing age. According to the scatter plot, select the regression equations as follows: logarithmic equation, $\mathrm{S}$-shaped equation, inverse equation, and power equation. The $\mathrm{C} / \mathrm{T}$ ratio is $1: 4$, the logarithmic equation and the $\mathrm{S}$-shaped equation have a high degree of regression, and the adjusted coefficients of determinations are 0.971 and 0.960 . The $F$ value of the logarithmic regression is 100.8506 ; the $p$ values are $0.0098<$ 0.01 , showing that the significance of the logarithmic is extremely great. The C/T ratio is 1:6, the logarithmic regression equation and the power equation have a high degree of regression, and the adjusted coefficients of determinations are 0.980 and 0.984 . The $F$ values are 147.1173 and 187.3661 , and the $p$ values are 0.0067 and 0.0053. In summary, the UCS of CUTB has a logarithmic relationship with curing age, and the regression equation is as follows:

$$
\begin{array}{lll}
\mathrm{C} / \mathrm{T} & 1: 4 & P=1.1339+1.1607 \ln T \\
\mathrm{C} / \mathrm{T} & 1: 6 & P=0.7105+0.8172 \ln T .
\end{array}
$$

According to the regression equation, the regression values corresponding to different observation values are calculated, and residual error analysis is performed. The specific calculation results are shown in Figure 7 and Table 4:

Analyzing the residual error of the regression equation, it can be seen that the observation value and the regression value are very small, but the residual value has a unit and cannot be directly used for comparative analysis. Generally, the residual values are standardized, and it follows the standard normal distribution $\mathrm{N}(0,1)$. The standardized residuals of the regression equations of UCS and curing age are all within the interval of $-2 \sim+2$ and contain randomness, indicating the equation is normal.

\section{XRD Analysis of CPB}

Figure 8 shows the XRD spectrum of the ultra-fine tailings and the classified tailings under the same conditions (C/T ratio $1: 4$, mass concentration $70 \%$, and curing age of 3 days). The $\mathrm{SiO}_{2}$ diffraction peak can be clearly seen from the figures because the main component of $\mathrm{CPB}$ is $\mathrm{SiO}_{2}$, which accounts for about $40 \%$ of the total mass. On the other hand, most $\mathrm{SiO}_{2}$ particles are inert materials, which act as aggregate and do not participate in the hydration reaction. The main hydration products in CUTB are C-S-H and AFt. Among them, AFt belongs to the crystals and has obvious diffraction peaks and $\mathrm{C}-\mathrm{S}-\mathrm{H}$ is a mostly amorphous hydrate with poor crystallinity. Moreover, there is a broad, convex hull background under the diffraction peaks of $2 \theta$ between $20^{\circ}$ and $45^{\circ}$. In contrast, the XRD spectrum of CCTB can observe not only AFt crystals and C-S-H but also obvious diffraction peaks of $\mathrm{Ca}(\mathrm{OH})_{2}$ crystals.

The analysis shows that the content of $\mathrm{Ca}(\mathrm{OH})_{2}$ crystals in the CUTB is very little or non-existent, and the area of the convex hull background of the spectrum is significantly larger than that of the CCTB. It shows that the hydration products and content of CUTB and CCTB are different, and the hydration reaction in the two kinds of $\mathrm{CPB}$ is different.

\section{SEM Analysis of CPB}

The CPB is mainly composed of three major types of materials, including unhydrated cement clinker, inert including in tailings and hydration product (Xu et al., 2013), and hydration products of Portland cement such as calcium silicate hydrate (C-S-H), ettringite (AFt), calcium aluminate sulfate hydrate (AFm), portlandite $\left(\mathrm{Ca}(\mathrm{OH})_{2}\right)$ and hydrogarnet $\left(\mathrm{C}_{3} \mathrm{AH}_{6}\right)$. The composition of C-S-H gel is complex, and it is usually assumed that the molecular formula is $\mathrm{C}_{3} \mathrm{~S}_{2} \mathrm{H}_{3}$. C-S-H gel has extremely poor crystallinity and its morphology is not fixed; most of them are fibrous, granular, and networked. The structural formula of AFt is $\left[\mathrm{Ca}_{3} \mathrm{Al}(\mathrm{OH})_{6} \cdot 12 \mathrm{H}_{2} \mathrm{O}\right]\left(\mathrm{SO}_{4}\right)_{16} \cdot \mathrm{H}_{2} \mathrm{O}$, with a high degree of crystallinity. The crystal is generally hexagonal prismatic, which grows into needle-like or columnar shape according to the growth space. The $\mathrm{Ca}(\mathrm{OH})_{2}$ has a good crystallinity with a hexagonal plate shape. It is unevenly distributed and the crystal size is $10-100 \mu \mathrm{m}$ (Fall et al., 2005).

Figures 9A,B are SEM images of CUTB and CCTB under the same conditions ( $\mathrm{C} / \mathrm{T}$ ratio $1: 4$, mass concentration $70 \%$, and curing age of 3 days). It can be seen from the figure that there are 

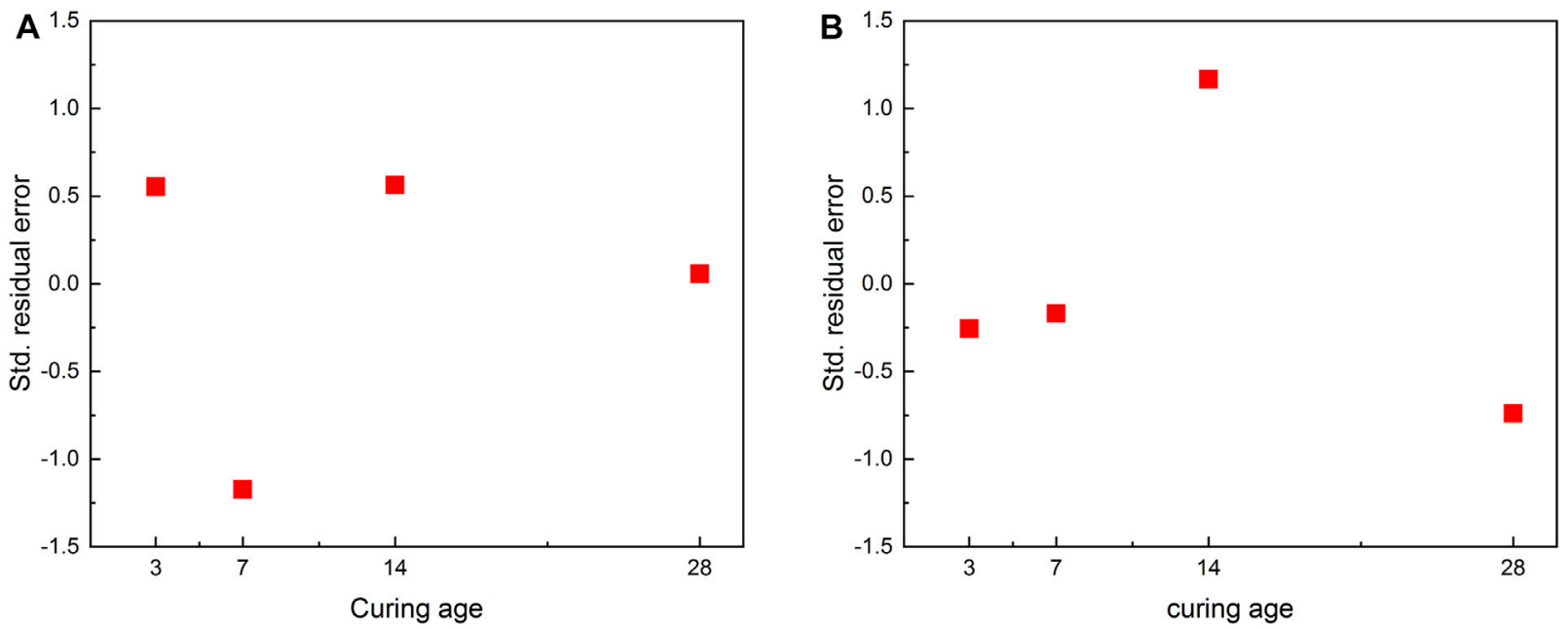

FIGURE 7 | Standardized residual error of regression equation: (A) C/T ratio 1:6; (B) C/T ratio 1:4.

TABLE 4 | Regression value and residual error analysis.

\begin{tabular}{ccccc} 
C/T ratio & Observation value & Regression value & Residual error & Standardized residual error \\
\hline $1: 4$ & 2.36 & 2.4091 & -0.0491 & -0.2564 \\
& 3.36 & 3.3925 & -0.0325 & -0.1697 \\
& 4.42 & 4.197 & 0.223 & 1.1656 \\
$1: 6$ & 4.86 & 5.0015 & -0.1415 & -0.7395 \\
& 1.67 & 1.6083 & 0.0617 & 0.553 \\
& 2.17 & 2.3008 & -0.1308 & -1.1723 \\
& 2.93 & 2.8672 & 0.0628 & 0.5628 \\
& 3.44 & 3.4337 & 0.0063 & 0.0566
\end{tabular}
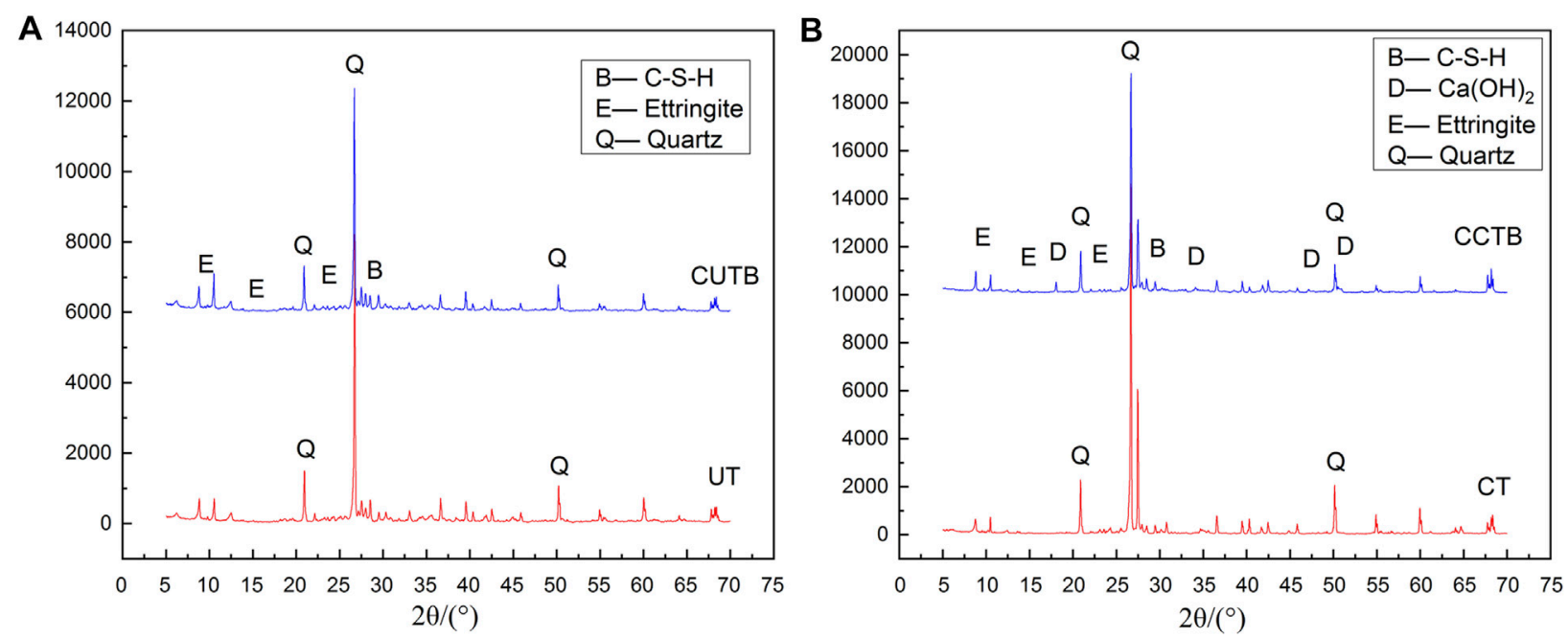

FIGURE 8 | XRD spectrum of CPB with S/W ratio 1:4 and curing age of 3 days: (A) CUTB; (B) CCTB. 
A

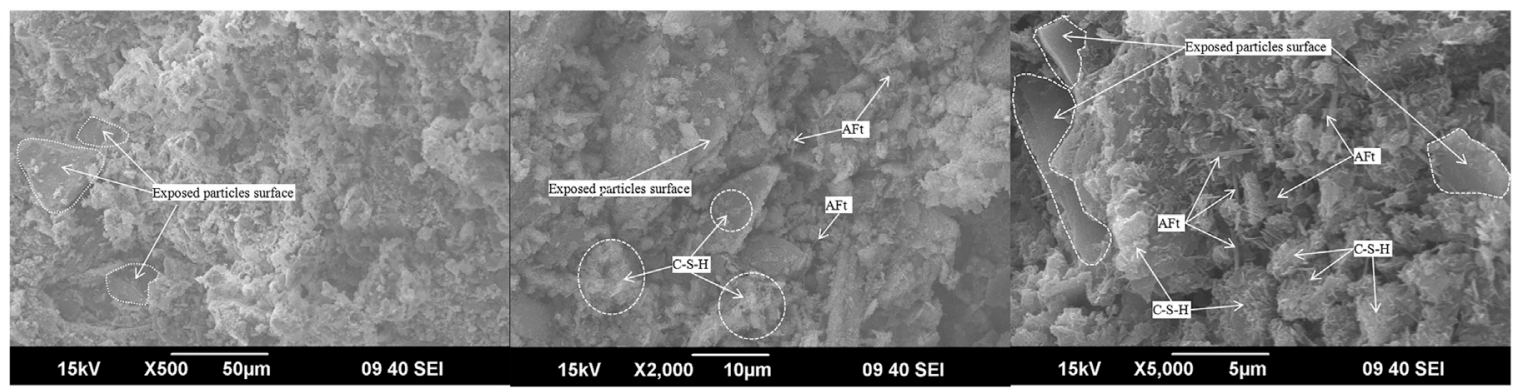

B

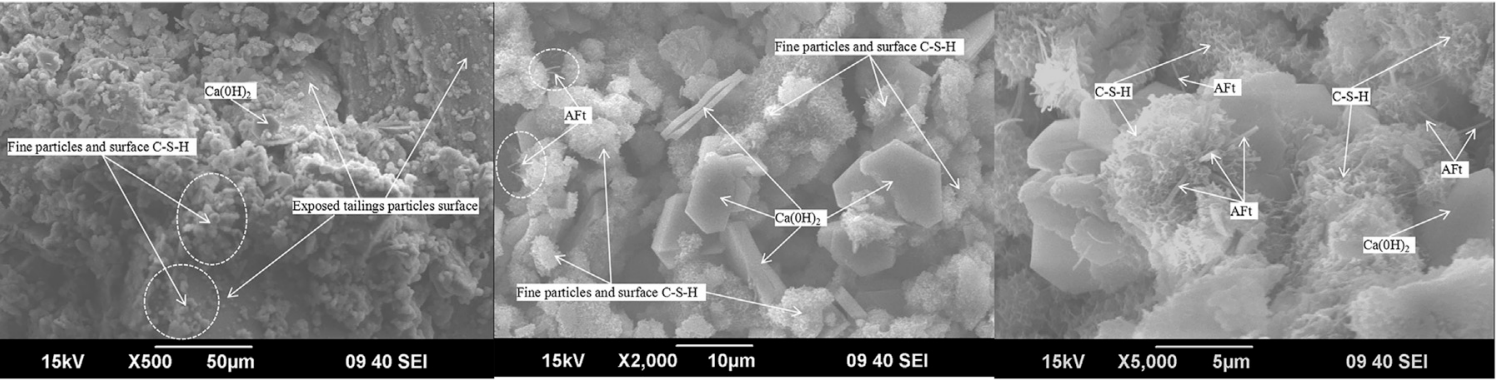

C

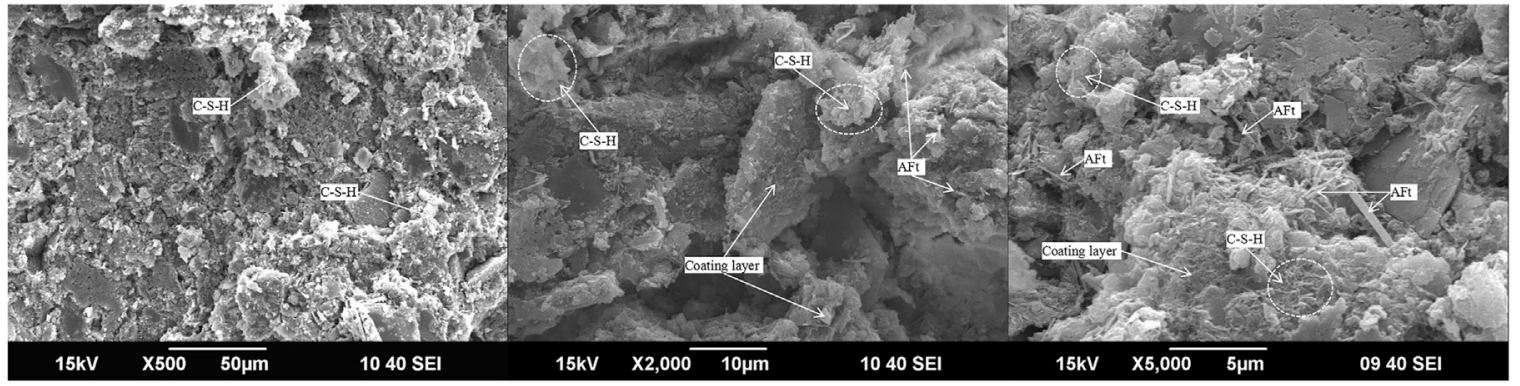

D
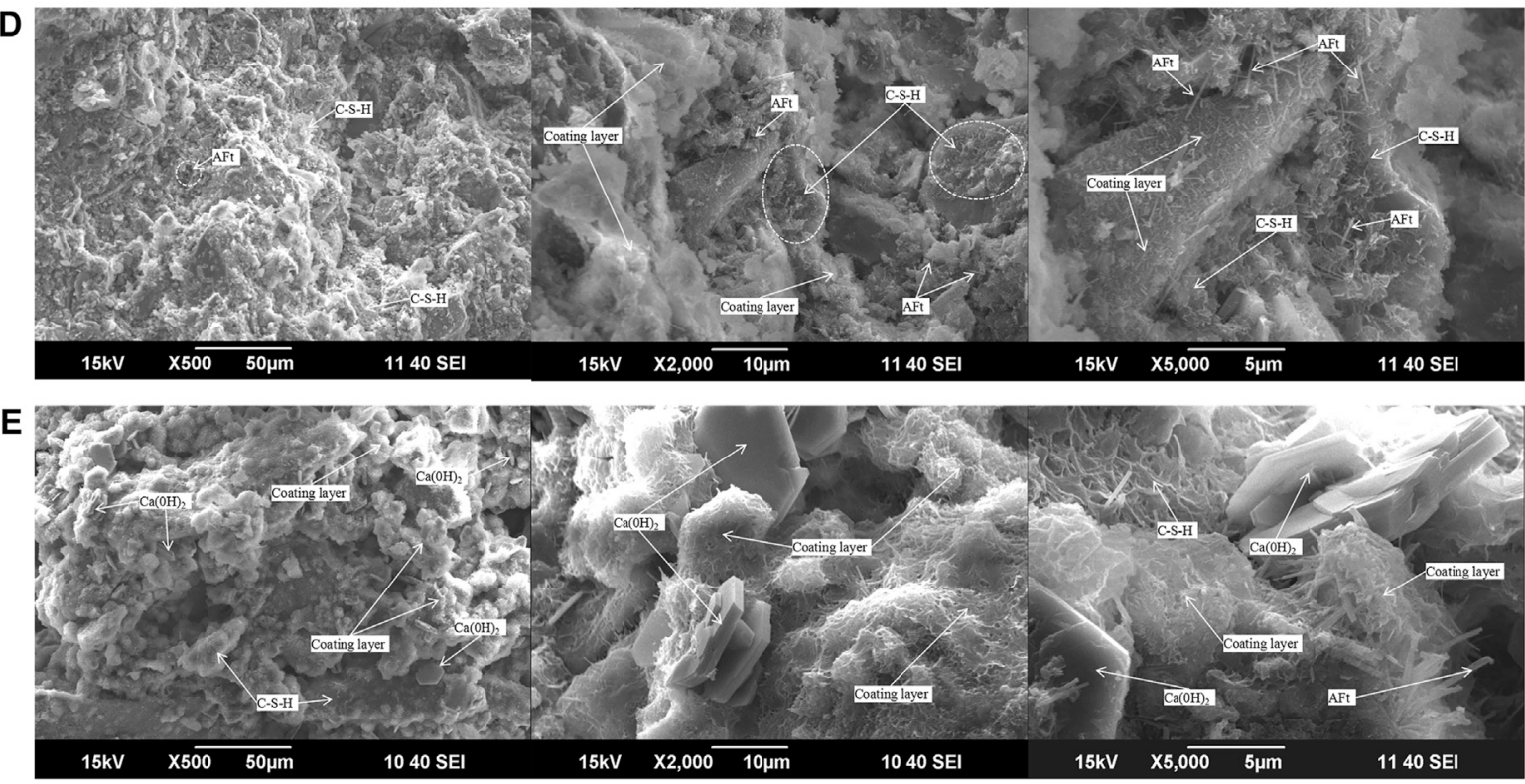

FIGURE 9 |SEM images of CPB with different $C / T$ ratio and curing age: (A) CUTB, $C / T$ ratio 1:4, curing age of 3 days; (B) CCTB, C/T ratio 1:4, curing age of 3 days; (C) CUTB, C/T ratio 1:4, curing age of 7 days; (D) CUTB, C/T ratio 1:4, curing age of 28 days; (E) CCTB, C/T ratio 1:4, curing age of 28 days. 
obvious hydration products in the CPB in the early curing age, but the morphology of the hydration products is different between the CUTB and the CCTB. In the CUTB, the C-S-H gel mostly wraps fine particles and ultra-fine particles in a network shape or attaches to the surface of coarse particles in a fibrous; the AFt crystals are randomly distributed on the surface of the particles and in tiny pores, and length is about $1 \sim 3 \mu \mathrm{m}$. In the CCTB, the C-S-H gel basically exists on the surface of fine particles and ultra-fine particles, the AFt crystals are mostly perpendicular to the surface of fine particles and ultra-fine particles, and the length is about $1 \sim 3 \mu \mathrm{m}$. The $\mathrm{Ca}(\mathrm{OH})_{2}$ crystals are randomly filled in the fine pores and micro-pores, with a size of about $5-10 \mu \mathrm{m}$. No obvious $\mathrm{Ca}(\mathrm{OH})_{2}$ crystals are observed in the CUTB, it can be seen that the hydration products in the CUTB and CCTB are different, and the hydration reactions that occur are also different. It shows that the particle size of tailings affects the hydration process of the $\mathrm{CPB}$, and the distribution and morphology of the hydration products change due to the difference in particle size.

Figures 9C,D are SEM images of CUTB and CCTB under the same conditions (C/T ratio $1: 4$, mass concentration $70 \%$, and curing age of 28 days). According to the hydration mechanism of the cement paste, the hydration reaction continues at 28 days of curing age, the hydration rate decreases, the hydration product grows slowly, and the internal structure of $\mathrm{CPB}$ is basically formed. However, the morphology of the hydration products and internal structure of CUTB and CCTB are still different. In the CUTB, the C-S-H gel forms a coating layer around fine particles and ultra-fine particles, and grows outwards. At the same time, it grows in a network on the surface of the coarse particles and connects the fine particles and ultra-fine particles with the coarse particles to form a dense three-dimensional whole. The AFt crystals are distributed on the surface of coarse particles and tiny pores, and the length is about $1 \sim 3 \mu \mathrm{m}$. In the CCTB, the C-S-H gel forms a coating layer around fine particles and ultra-fine particles, grows outward with particles as the center, and connects the particles into a whole. The AFt crystals mostly exist perpendicular to the surface of fine particles and ultrafine particles, and the length is about $1 \sim 3 \mu \mathrm{m}$. The $\mathrm{Ca}(\mathrm{OH})_{2}$ crystals are distributed disorderly in the CCTB: some are wrapped by C-S-H gel and some are filled into pores.

There are no obvious $\mathrm{Ca}(\mathrm{OH})_{2}$ crystals in the CUTB at the curing age of 28 days. It can be seen that the difference of hydration reaction between the two CPB always exists, indicating that the particle size of tailings has always affected the hydration process in the curing process, and there is the difference in the structure of the $\mathrm{CPB}$ and the morphology of the hydration products. Although the $\mathrm{C}-\mathrm{S}-\mathrm{H}$ gel forms a coating layer after curing 28 days, the $\mathrm{C}-\mathrm{S}-\mathrm{H}$ gel grows with independent particles as the center in the CCTB, with the increasing thickness of the coating layer. Particles contact with each other and continue to grow at the contact point and finally form a three-dimensional whole, and obvious particle profile can be observed in the figure. In the CUTB, fine particles and ultra-fine particles are wrapped in C-S-H gel to form aggregates, and independent fine particles and ultra-fine particles are not observed. The aggregates connect with adjacent coarse particles to form a dense whole.
Figures 9A,D,E are SEM images of CUTB at different curing ages under the same proportion (C/T ratio 1:4, mass concentration $70 \%$, and curing age of 28 days). It can be seen from the figures that the morphology of C-S-H gel changes with the curing age and has regularity. At the curing age of 3 days, the $\mathrm{C}-\mathrm{S}-\mathrm{H}$ gel is centered on the fine particles and ultra-fine particles and grows on the surface of the surface in a network shape, and the surface of the coarse particles is exposed and no obvious C-S-H gel is observed. At the curing age of 7 days, with the continuous growth of the C-S-H gel outside the coating layer, the particles and the $\mathrm{C}-\mathrm{S}-\mathrm{H}$ gel form agglomerates where the fine particles and ultra-fine particles are dense, and there are obvious network-shaped C-S-H gel on the surface of local coarse particles. The morphology of AFt crystals changed with the growth of the curing age, AFt crystals are mainly distributed on the particle surface and tiny pores, and the size does not change significantly, about $1 \sim 3 \mu \mathrm{m}$.

\section{Hydration Reaction Mechanism of CUTB}

After the cement, ultra-fine tailings, and water were mixed, the chemical reaction will be produced immediately. The first is the rapid dissolution of cement clinker minerals:

$$
\begin{aligned}
\mathrm{C}_{3} \mathrm{~A} & \rightarrow \mathrm{Ca}^{2+}+\mathrm{Al}(\mathrm{OH})_{4}^{-}+\mathrm{OH}^{-} \\
f-\mathrm{CaO} & \rightarrow \mathrm{Ca}^{2+}+\mathrm{OH}^{-} \\
\mathrm{CaSO}_{4} & \rightarrow \mathrm{Ca}^{2+}+\mathrm{SO}_{4}^{2-} \\
\mathrm{C}_{3} \mathrm{~S} & \rightarrow \mathrm{Ca}^{2+}+\mathrm{OH}^{-}+\mathrm{C}-\mathrm{S}-\mathrm{H}(\mathrm{m}) .
\end{aligned}
$$

At this moment, the liquid phase of cement ultra-fine tailings backfill slurry contains various ions: $\mathrm{Ca}^{2+}, \mathrm{OH}^{-}, \mathrm{Al}(\mathrm{OH})^{4-}, \mathrm{SO}_{4}{ }^{2-}$, etc. The slurry is alkaline, and the hydration reaction of CUTB is carried out under an alkaline environment. $\mathrm{C}_{3} \mathrm{~A}$ is one of the main components of cement, and immediate hydration reaction when it is mixed with water rapidly produces $\mathrm{C}_{4} \mathrm{AH}_{13}$, immediately reacting with gypsum to form AFt (Myers et al., 2017):

$$
\begin{gathered}
\mathrm{C}_{3} \mathrm{~A}+\mathrm{Ca}(\mathrm{OH})_{2}+\mathrm{H}_{2} \mathrm{O} \rightarrow \mathrm{C}_{4} A H_{13} \\
\mathrm{C}_{4} A \mathrm{H}_{13}+3 \mathrm{C} \overline{\mathrm{S}} \mathrm{H}_{2}+\mathrm{H}_{2} \mathrm{O} \rightarrow A F_{t}+\mathrm{CH} .
\end{gathered}
$$

The hydration reaction rate of $\mathrm{C}_{3} \mathrm{~S}$ is slightly slower than that of $\mathrm{C}_{3} \mathrm{~A}$ because the pore solution of $\mathrm{C}_{3} \mathrm{~S}$ particles quickly reaches saturation, inhibiting the dissolution of $\mathrm{C}_{3} \mathrm{~S}$ particles. However, the formation and growth of hydration such as $\mathrm{C}-\mathrm{S}-\mathrm{H}$ take a certain time, thus hindering the hydration of $\mathrm{C}_{3} \mathrm{~S}$ particles, but this duration of this stage is very short (Scrivener et al., 2019). With the increase of curing age, the hydration reaction rate of $\mathrm{C}_{3} \mathrm{~S}$ gradually increases and reaches the maximum. The hydration product of $\mathrm{C}_{3} \mathrm{~S}$ is mainly C-S-H gel, and the concentration of $\mathrm{Ca}$ $(\mathrm{OH})_{2}$ solution is increased continuously by the generated large amount of $\mathrm{Ca}^{2+}$ iron and $\mathrm{OH}^{-}$iron:

$$
\mathrm{C}_{3} \mathrm{~S}+\mathrm{H}_{2} \mathrm{O} \rightarrow \mathrm{C}-\mathrm{S}-\mathrm{H}+\mathrm{Ca}(\mathrm{OH})_{2} .
$$

Figures 8, 9A,B show that the hydration products of the CUTB and CCTB are different, indicating that not only does the cement itself undergoe a hydration reaction, but also other components of $\mathrm{CPB}$ participate in the hydration reaction. According to the results of XRD energy spectrum analysis of tailings, the ultra-fine particles in the ultra-fine tailings are amorphous, with high surface energy and certain potential 
activity, which can react with $\mathrm{Ca}(\mathrm{OH})_{2}$ in ultra-fine tailings filling slurry solution (Geng et al., 2017; Li et al., 2019):

$$
\begin{aligned}
& \mathrm{SiO}_{2}+\mathrm{Ca}(\mathrm{OH})_{2}+\mathrm{H}_{2} \mathrm{O} \rightarrow \mathrm{C}-\mathrm{S}-\mathrm{H} \\
& \mathrm{Al}_{2} \mathrm{O}_{3}+\mathrm{Ca}(\mathrm{OH})_{2}+\mathrm{H}_{2} \mathrm{O} \rightarrow \mathrm{C}-\mathrm{A}-\mathrm{H} .
\end{aligned}
$$

Therefore, some of the mineral particles in the UT, such as $\mathrm{SiO}_{2}$ and $\mathrm{Al}_{2} \mathrm{O}_{3}$, do not act as a backfill aggregate but participate as active materials in the hydration reaction. It increased the amount of C-S-H and C-A-H and consumed $\mathrm{Ca}(\mathrm{OH})_{2}$.

Due to the existence of secondary hydration reaction in the CUTB, this consumes $\mathrm{Ca}^{2+}$ ions, $\mathrm{OH}^{-}$ions, and gypsum in the solution and increases the production of $\mathrm{C}-\mathrm{S}-\mathrm{H}$ gel and $\mathrm{AFt}$ crystals. Because of the decrease in the concentration of $\mathrm{Ca}^{2+}$ ions and $\mathrm{OH}^{-}$ions, the concentration of $\mathrm{Ca}(\mathrm{OH})_{2}$ can not be supersaturated, resulting in very little or not $\mathrm{Ca}(\mathrm{OH})_{2}$ crystals formation in the CUTB.

With the curing age increasing, gypsum is gradually consumed, making the $\mathrm{C}_{3} \mathrm{~A}$ in the CUTB not completely hydrated, and is exhausted. The reaction of AFt generated in the early curing age of CUTB with $\mathrm{C}_{4} \mathrm{AH}_{13}$ formed by hydration of $\mathrm{C}_{3} \mathrm{~A}$ produces $\mathrm{AFm}$ :

$$
\mathrm{AFt}+\mathrm{C}_{3} \mathrm{~A}+\mathrm{H}_{2} \mathrm{O} \rightarrow \mathrm{AFm} .
$$

The AFm generated by hydration reaction and the C-S-H gel coating layer on the surface of particles are mixed, where no AFm crystals could be observed on the SEM image. This reaction also consumes AFt, causing the AFt crystals to be converted into AFm without further growth, so the size of AFt crystals observed in the SEM image does not change significantly.

In summary, the hydration of CUTB is based on cement hydration, which is affected by ultra-fine tailings particles with potential activity, and can result in secondary hydration reaction, affect the hydration process, and change the hydration products and morphology.

\section{CONCLUSION}

In this study, UCS test of the CPB with different curing ages and different $\mathrm{C} / \mathrm{T}$ ratios was designed, and XRD energy spectrum and SEM image were carried out. The following conclusions were drawn in this study:

1) The UCS of the CUTB is significantly higher than the CCTB under the same conditions, and the greater the $\mathrm{C} / \mathrm{T}$ ratio and curing age, the greater the UCS difference value between the CUTB and CCTB. The variation laws of the CUTB and CCTB are different under the same mixing ratio; the UCS growth curve of the CUTB is approximately S-shaped and the UCS growth curve of the CCTB has an approximately convex shape.

2) There is a logarithmic relationship between the UCS of the CUTB and the curing age; the regression equation is as follows:

$$
\begin{array}{lll}
\mathrm{C} / \mathrm{T} & 1: 4 & P=1.1339+1.1607 \ln T \\
\mathrm{C} / \mathrm{T} & 1: 6 & P=0.7105+0.8172 \ln T
\end{array}
$$

The adjusted coefficient of determinations (ADJ $\mathrm{R}^{2}$ ) is 0.971 $(\mathrm{C} / \mathrm{T}$ ratio $1: 4)$ and $0.980(\mathrm{C} / \mathrm{T}$ ratio $1: 4)$, respectively, and passed the significance test and residual test equations.

3) The XRD energy spectrum shows that the hydration products and content of CUTB and CCTB are different. In the CUTB, the content of $\mathrm{Ca}(\mathrm{OH})_{2}$ crystals is very little or non-existent, but the content of the C-S-H gel is higher than the CCTB.

4) The particle size of tailings affects the hydration process of the $\mathrm{CPB}$ and the distribution and morphology of the hydration products. In the CUTB, no obvious $\mathrm{Ca}(\mathrm{OH})_{2}$ crystals are observed during the curing. The $\mathrm{C}-\mathrm{S}-\mathrm{H}$ gel forms a coating layer around fine particles and ultra-fine particles and grows to form aggregates. In the CCTB, the $\mathrm{C}-\mathrm{S}-\mathrm{H}$ gel grows with independent particles as the center, and particles contact each other by C-S-H gel.

5) The ultra-fine tailings particles in the CUTB have potential activity; in the alkaline environment-generated cement hydration, the active $\mathrm{SiO}_{2}$ and $\mathrm{Al}_{2} \mathrm{O}_{3}$ particles undergo secondary hydration reaction, $\mathrm{C}-\mathrm{S}-\mathrm{H}$ and $\mathrm{C}-\mathrm{A}-\mathrm{H}$ are generated while consuming $\mathrm{Ca}(\mathrm{OH})_{2}$, resulting in different hydration reactions of CUTB and CCTB, and the hydration products and morphology are also different.

6) It is well-known that the groundwater protection challenges related to cemented paste backfill have become a worldwide issue in mining areas (Chen et al., 2021). Thus, the leaching risk of CUTB to groundwater will be further studied in our future studies.

\section{DATA AVAILABILITY STATEMENT}

The original contributions presented in the study are included in the article/Supplementary Materials; further inquiries can be directed to the corresponding author.

\section{AUTHOR CONTRIBUTIONS}

GD contributed to the experiments scheme and discuss the results. CC contributed to the conception of the study. $\mathrm{LiH}$ contributed to the experiments and wrote the manuscript. $\mathrm{LuH}$ and $\mathrm{ZY}$ discussed the results and contributed to the final manuscript.

\section{FUNDING}

This work was supported by the National Natural Science Foundation of China (No. 51774137), the Department of Education of Hebei Province (No. ZD2015020), the Natural Science Foundation of Hebei Province (Nos. E2021209006 and E2019209326), the "333" Talent Project of Hebei Province, China (No. 202001011), and State Key Laboratory of Process Automation in Mining and Metallurgy and Beijing Key Laboratory of Process Automation in Mining and Metallurgy (No. BGRIMM-KZSKL-2018). 


\section{REFERENCES}

Benzaazoua, M., Fall, M., and Belem, T. (2004). A Contribution to Understanding the Hardening Process of Cemented Pastefill. Minerals Eng. 17, 141-152. doi:10.1016/j.mineng.2003.10.022

Chen, Q., Sun, S., Liu, Y., Qi, C., Zhou, H., and Zhang, Q., (2021). Experimental and Numerical Study on Immobilization and Leaching Characteristics of Fluoride from Phosphogypsum Based Cemented Paste Backfill. Int. J. Min Met. Mater. doi:10.1007/s12613-021-2274-6

Cihangir, F., Ercikdi, B., Kesimal, A., Turan, A., and Deveci, H. (2012). Utilisation of Alkali-Activated Blast Furnace Slag in Paste Backfill of High-Sulphide Mill Tailings: Effect of Binder Type and Dosage. Minerals Eng. 30, 33-43. doi:10.1016/j.mineng.2012.01.009

Deng, D. Q., Liu, L., Yao, Z. L., Song, K. I.-I. L., and Lao, D. Z. (2017a). A Practice of Ultra-fine Tailings Disposal as Filling Material in a Gold Mine. J. Environ. Manage. 196, 100-109. doi:10.1016/j.jenvman.2017.02.056

Deng, X. J., Klein, B., Hallbom, D. J., de Wit, B., and Zhang, J. X. (2018a). Influence of Particle Size on the Basic and Time-dependent Rheological Behaviors of Cemented Paste Backfill. J. Materi Eng. Perform. 27, 3478-3487. doi:10.1007/ s11665-018-3467-7

Deng, X., Klein, B., Tong, L., and de Wit, B. (2018b). Experimental Study on the Rheological Behavior of Ultra-fine Cemented Backfill. Construction Building Mater. 158, 985-994. doi:10.1016/j.conbuildmat.2017.05.085

Deng, X., Zhang, J., Klein, B., Zhou, N., and deWit, B. (2017b). Experimental Characterization of the Influence of Solid Components on the Rheological and Mechanical Properties of Cemented Paste Backfill. Int. J. Mineral Process. 168, 116-125. doi:10.1016/j.minpro.2017.09.019

Doherty, J. P., Hasan, A., Suazo, G. H., and Fourie, A. (2015). Investigation of Some Controllable Factors that Impact the Stress State in Cemented Paste Backfill. Can. Geotech. J. 52, 1901-1912. doi:10.1139/cgj-2014-0321

Ercikdi, B., Baki, H., and İzki, M. (2013). Effect of Desliming of Sulphide-Rich Mill Tailings on the Long-Term Strength of Cemented Paste Backfill. J. Environ. Manage. 115, 5-13. doi:10.1016/j.jenvman.2012.11.014

Ercikdi, B., Kesimal, A., Cihangir, F., Deveci, H., and Alp, İ. (2009). Cemented Paste Backfill of Sulphide-Rich Tailings: Importance of Binder Type and Dosage. Cement and Concrete Composites. 31, 268-274. doi:10.1016/ j.cemconcomp.2009.01.008

Fall, M., Benzaazoua, M., and Ouellet, S. (2005). Experimental Characterization of the Influence of Tailings Fineness and Density on the Quality of Cemented Paste Backfill. Minerals Eng. 18, 41-44. doi:10.1016/j.mineng.2004.05.012

Fall, M., Benzaazoua, M., and Saa, E. G. (2008). Mix Proportioning of Underground Cemented Tailings Backfill. Tunnelling Underground Space Tech. 23, 80-90. doi:10.1016/j.tust.2006.08.005

Fall, M., Célestin, J. C., Pokharel, M., and Touré, M. (2010). A Contribution to Understanding the Effects of Curing Temperature on the Mechanical Properties of Mine Cemented Tailings Backfill. Eng. Geology. 114, 397-413. doi:10.1016/j.enggeo.2010.05.016

Geng, G., Myers, R. J., Li, J., Maboudian, R., Carraro, C., Shapiro, D. A., et al. (2017). Aluminum-induced Dreierketten Chain Cross-Links Increase the Mechanical Properties of Nanocrystalline Calcium Aluminosilicate Hydrate. Sci. Rep. 7 (1). doi:10.1038/srep44032

Helinski, M., Fahey, M., and Fourie, A. (2007). Numerical Modeling of Cemented Mine Backfill Deposition. J. Geotech. Geoenviron. Eng. 133, 1308-1319. doi:10.1061/(asce)1090-0241(2007)133:10(1308)

Jiang, H., Fall, M., Li, Y., and Han, J. (2019). An Experimental Study on Compressive Behaviour of Cemented Rockfill. Construction Building Mater. 213, 10-19. doi:10.1016/j.conbuildmat.2019.04.061

Kawatra, S. K. (2017). Mineral Processing and Extractive Metallurgy Review. An Int. J. Min. Proc. Ext. Met. Rev. 38. doi:10.1080/08827508.2017.1390966

Ke, X., Hou, H., Zhou, M., Wang, Y., and Zhou, X. (2015). Effect of Particle Gradation on Properties of Fresh and Hardened Cemented Paste Backfill. Construction Building Mater. 96, 378-382. doi:10.1016/ j.conbuildmat.2015.08.057

Ke, X., Zhou, X., Wang, X., Wang, T., Hou, H., and Zhou, M. (2016). Effect of Tailings Fineness on the Pore Structure Development of Cemented Paste Backfill. Construction Building Mater. 126, 345-350. doi:10.1016/ j.conbuildmat.2016.09.052
Kesimal, A., Ercikdi, B., and Yilmaz, E. (2003). The Effect of Desliming by Sedimentation on Paste Backfill Performance. Minerals Eng. 16, 1009-1011. doi:10.1016/S0892-6875(03)00267-X

Li, J., Geng, G., Myers, R., Yu, Y.-S., Shapiro, D., Carraro, C., et al. (2019). The Chemistry and Structure of Calcium (Alumino) Silicate Hydrate: A Study by XANES, Ptychographic Imaging, and Wide- and Small-Angle Scattering. Cement Concrete Res. 115, 367-378. doi:10.1016/ j.cemconres.2018.09.008

Liu, L., Fang, Z., Qi, C., Zhang, B., Guo, L., and Song, K. I.-I. L. (2019). Numerical Study on the Pipe Flow Characteristics of the Cemented Paste Backfill Slurry Considering Hydration Effects. Powder Tech. 343, 454-464. doi:10.1016/ j.powtec.2018.11.070

Lu, H., Qi, C., Chen, Q., Gan, D., Xue, Z., and Hu, Y. (2018). A New Procedure for Recycling Waste Tailings as Cemented Paste Backfill to Underground Stopes and Open Pits. J. Clean. Prod. 188, 601-612. doi:10.1016/ j.jclepro.2018.04.041

Myers, R. J., Geng, G., Li, J., Rodríguez, E. D., Ha, J., Kidkhunthod, P., et al. (2017). Role of Adsorption Phenomena in Cubic Tricalcium Aluminate Dissolution. Langmuir 33 (1), 45-55. doi:10.1021/acs.langmuir.6b03474

Nircoshan, N., Sivakugan, N., and Veenstra, R. L. (2017). Laboratory Study on Strength Development in Cemented Paste Backfills. J. Mater. Civil. Eng. 29. doi:10.1061/(asce)mt.1943-5533.0001848

Ouellet, S., Bussière, B., Aubertin, M., and Benzaazoua, M. (2007). Microstructural Evolution of Cemented Paste Backfill: Mercury Intrusion Porosimetry Test Results. Cement Concrete Res. 37, 1654-1665. doi:10.1016/ j.cemconres.2007.08.016

Qiu, J., Yang, L., Sun, X., Xing, J., and Li, S. (2017). Strength Characteristics and Failure Mechanism of Cemented Super-Fine Unclassified Tailings Backfill. Minerals 7, 58. doi:10.3390/min7040058

Scrivener, K., Ouzia, A., Juilland, P., and Kunhi Mohamed, A. (2019). Advances in Understanding Cement Hydration Mechanisms. Cement Concrete Res. 124, 105823. doi:10.1016/j.cemconres.2019.105823

Wang, C., Harbottle, D., Liu, Q., and Xu, Z. (2014). Current State of fine mineral Tailings Treatment: A Critical Review on Theory and Practice. Minerals Eng. 58, 113-131. doi:10.1016/j.mineng.2014.01.018

Wang, X.-m., Zhao, B., and Zhang, Q.-l. (2009). Cemented Backfill Technology Based on Phosphorous gypsum. J. Cent. South. Univ. Technol. 16, 285-291. doi:10.1007/s11771-009-0049-8

Wolff, A. P., da Costa, G. M., and de Castro Dutra, F. (2010). A Comparative Study of Ultra-Fine Iron Ore Tailings from Brazil. Mineral. Process. Extractive Metall. Rev. 32, 47-59. doi:10.1080/08827508.2010.530718

Xu, W. B., Du, J. H., Song, W. D., and Cheng, H. Y. (2013). Experiment on the Mechanism of Consolidating Backfill Body of Extra-fine Grain Unclassified Tailings and Cementitious Materials. Rock. Soil Mech. 8, 2295-2302. doi:10.16285/j.rsm.2013.08.013

Xue, G., Yilmaz, E., Song, W., and Cao, S. (2018). Compressive Strength Characteristics of Cemented Tailings Backfill with Alkali-Activated Slag. Appl. Sci. 8, 1537. doi:10.3390/app8091537

Yang, L., Qiu, J., Jiang, H., Hu, S., Li, H., and Li, S. (2017). Use of Cemented SuperFine Unclassified Tailings Backfill for Control of Subsidence. Minerals 7, 216. doi: $10.3390 / \min 7110216$

Yilmaz, E., Belem, T., and Benzaazoua, M. (2012). One-Dimensional Consolidation Parameters of Cemented Paste Backfills/Parametry Jednowymiarowej Konsolidacji Podsadzki W Postaci Cementowej Pasty. Gospod. Surowcami. Min. 28, 29-45. doi:10.2478/v10269-012-0030-2

Yin, S., Wu, A., Hu, K., Wang, Y., and Zhang, Y. (2012). The Effect of Solid Components on the Rheological and Mechanical Properties of Cemented Paste Backfill. Minerals Eng. 35, 61-66. doi:10.1016/j.mineng.2012.04.008

Yılmaz, T., Ercikdi, B., Karaman, K., and Külekçi, G. (2014). Assessment of Strength Properties of Cemented Paste Backfill by Ultrasonic Pulse Velocity Test. Ultrasonics 54, 1386-1394. doi:10.1016/j.ultras.2014.02.012

Zhao, J.-w., Wang, X.-m., Peng, K., and Li, S. (2017a). Utilization of Foaming Technology in Cemented Paste Backfill of High-Mud Superfine Unclassified Tailings. Adv. Mater. Sci. Eng. 2017, 1-7. doi:10.1155/2017/6157869

Zheng, J., Zhu, Y., and Zhao, Z. (2016). Utilization of limestone Powder and WaterReducing Admixture in Cemented Paste Backfill of Coarse Copper Mine Tailings. Construction Building Mater. 124, 31-36. doi:10.1016/ j.conbuildmat.2016.07.055 
Zhou, K.-p., Gao, R., and Gao, F. (2017b). Particle Flow Characteristics and Transportation Optimization of Superfine Unclassified Backfilling. Minerals 7, 6. doi:10.3390/min7010006

Conflict of Interest: The authors declare that the research was conducted in the absence of any commercial or financial relationships that could be construed as a potential conflict of interest.

Publisher's Note: All claims expressed in this article are solely those of the authors and do not necessarily represent those of their affiliated organizations, or those of the publisher, the editors and the reviewers. Any product that may be evaluated in this article, or claim that may be made by its manufacturer, is not guaranteed or endorsed by the publisher.

Copyright () 2021 Deqing, Hongbao, Chao, Hongjian and Youzhi. This is an openaccess article distributed under the terms of the Creative Commons Attribution License (CC BY). The use, distribution or reproduction in other forums is permitted, provided the original author(s) and the copyright owner(s) are credited and that the original publication in this journal is cited, in accordance with accepted academic practice. No use, distribution or reproduction is permitted which does not comply with these terms. 